\title{
Coastal Dunes Mobility Integration and Characterization: Developing of a Flexible Volume Computing Method
}

\author{
Benoît Guillot $^{1 *}$, Jonathan Musereau², Bruno Dalaine ${ }^{3}$, Joseph Morel $^{3}$ \\ ${ }^{1}$ University of Bordeaux, Pessac, France \\ ${ }^{2}$ Geography, Rennes, France \\ ${ }^{3}$ Geometer (DPLG), Rennes, France \\ Email: *benoit.guillot@u-bordeaux.fr
}

How to cite this paper: Guillot, B., Musereau, J., Dalaine, B. and Morel, J. (2018) Coastal Dunes Mobility Integration and Characterization: Developing of a Flexible Volume Computing Method. Journal of Geographic Information System, 10, 503-520. https://doi.org/10.4236/igis.2018.105027

Received: August 30, 2018

Accepted: October 13, 2018

Published: October 16, 2018

Copyright $\odot 2018$ by authors and Scientific Research Publishing Inc. This work is licensed under the Creative Commons Attribution-NonCommercial International License (CC BY-NC 4.0).

http://creativecommons.org/licenses/by-nc/4.0/

\begin{abstract}
Coastal dunes are among the most complex interfaces to study in the world. Improving the knowledge of their morphodynamics is essential to better understand the present evolutions and try to anticipate future. The recent use of the new vectors that are drones, UAV and UAS, improves the temporal and spatial resolutions of geomatic data acquired on these environments. Many studies attempt to measure the sedimentary variations that occur from one date to another by the use of differential volumes. In particular, they make it possible to understand the roles of storms, sometimes erosive, as well as the possible morphological responses of associated reconstruction periods. One of the primary methods for calculating volume evolutions is the assessment of a vertical delimitation of the dune toe. However, it is difficult to limit mobile and variable environment, temporally and spatially, to a simple vertical topographic delimitation. This study was realized to estimate the error induced by the use of the vertical threshold method. In the examples that were done, this error was far from being negligible and might in some cases exceed the evolutions of measured volumes. In overcoming this problem, an alternative method was developed. It was the seemingly better adaptability to these mobile environments that are the coastal dunes.
\end{abstract}

\section{Keywords}

Coastal Sand Dune, Volume Computing, Beach-Dune System Evolution

\section{Introduction}

Coastal dunes are part of the most complex natural boundaries to study [1]. 
Anthropogenic pressures on these environments, as urbanization and tourism, involve more vulnerability to climate change: sea level rise, storm impacts and other coastal hazards [2] [3] [4]. This paper deals with improvements in scientific knowledge and data collection about beach and dune behaviour. Most of the studies dealing with this issue are based on spatial analysis, through the use of Geographic Information System (GIS). These data can be aerial photos, Digital Elevation Models (DEM), topographic features and many other elements allowing interpretation of spatial dynamics and processes [5]-[10]. In the domain of coastal dunes survey, these tools give us the opportunity to better estimate morphological evolutions: coastline position [6] [11] [12], vegetation cover [13] [14] and sediment budgets (defined as the balance between changes in the volume of sediment stored in the beach and dune system and the sum of the volumes of sediment entering or leaving the system) [15]-[21].

Our study focuses on available methods dealing with the calculation of dune volume variations due to storm impacts [20] [22] [23] and the following post-traumatic reconstructions [21] [24] [25] [26]. A large part of the studies aiming at calculating coastal dune volumes is based on a spatial extent of the foredune and on well-used parameters that are, in practice, quite easy to be applied: cross-shore profiles, a vertical limit of the dune toe, a point of no mobility located on the grey dune. Those studies poorly described or computed associated error to the vertical limit method. Field observation, especially at high frequency and spatial resolutions, shows that beach and white dune are such mobile environments in which behavior modeling with fixed delimitations doesn't work. We assume that, without integrating a more complex set of parameters, precious information can be lost, so that, in certain cases, analysis and interpretations ensued from this erroneous data compilation can be considered as ineffective [1] [6] [7] [21] [27].

Our study aims to better assess bias between a classic method of volume calculation (using arbitrary vertical limits) and field reality, and then try to quantify associated errors. To that end, a geomatic protocol of verification, using Lidar (laser detection and ranging) acquisition and UAV (Unmanned Aerial Vehicle) survey, is developed and a new method of volume calculation, using an adapted version of the "cut and fill" topometric technic of measurement, is tested on two control sites located on the west coast of France.

\section{Field Site}

Study sites are situated on the central part of the French Atlantic coast (Figure 1). The first one, the beach of Plaisance, is a sheltered bay located on the East coast of Oleron Island. The second one, Truc-Vert, is an exposed beach located on the Aquitanian coast. Both of them are evolving in a macrotidal environment, with a tidal range of about $5.0 \mathrm{~m}$. In this region, wave climate is varying in function of the season, with a dominant West-North-West direction implying a southward littoral drift. Meteorological data from the local weather stations 




Figure 1. Study sites localization and presentation along the Bay of Biscay (A), for Plaisance (B), and Truc-Vert (C), with associated aerial photos (B' and C'), and the wind configuration (D).

indicate that West winds dominate the winter season while sea breeze takes place during summer.

\subsection{Plaisance}

The site of Plaisance is composed of a large beach, and a low elevated foredune protecting a pine forest, surrounded by the cove of La Malconche to the North and the head of Les Saumonards to the East. In this part of the Isle of Oleron, swell is refracted and waves have mainly lost their energy when they break in front of Plaisance. Only storm conditions and/or long period swells can produce waves exceeding $1.0 \mathrm{~m}$. The beach and dune system is composed of fine sands $(200$ to $350 \mu \mathrm{m})$. The forest was planted during du $19^{\text {th }}$ century to preserve local population from sand invasions and coastal retreat. Nowadays, coastline position is sustained by dikes and groynes erected during the second part of the $20^{\text {th }}$ century. More recently, a very energetic winter (2013-2014) caused repeated damages on the dune and several overflows in only a few months. Following this climatic anomaly, a dune recovery is observed. But the site remains vulnerable to storms, especially those impacting the coast during high spring tides.

\subsection{Truc-Vert}

The beach and dune morphology at Truc-Vert is representative of the straight shape of the Aquitanian coast. The prevailing dynamics are typically those observed on very exposed beaches, dominated by swell conditions. Indeed, if wave climate indicate an average significant wave height of 1.0 (summer) to $2.0 \mathrm{~m}$ (winter), storm waves are frequently able to exceed $5.0 \mathrm{~m}$ (and in rare cases $8 \mathrm{~m}$ ) nearby the coast. Rip currents are intense and play a key role in nearshore mor- 
phodynamics over this ridge and runnel system. The dune is composed of quite fine sediments (200 to $350 \mu \mathrm{m}$ ), mainly quartz. Compared with the Oleron site, foredune is large and well developed: average width of $200 \mathrm{~m}$ and more than 10 $\mathrm{m}$ high. The site is less impacted by anthropogenic activities, and any dike or groyne was built to maintain the coastline. However, reprofiling and planting of marram grass were frequent during the last decades. Thus, the foredune of Truc-Vert can be considered as a young and artificialized feature. Breaches are systematically filled after storms. The "terrible winter 2013-2014" caused a very intense coastal retreat and the formation of a sand cliff. Since then, beach and dune recovery are observed, with a high rate of sand deposition on the beach. Vegetation is comforting this process.

\section{Methods}

\subsection{Lidar Acquisition}

The campaigns were carried out by the National Geographical Institute (IGN), with the Litto 3D program (2010, at Plaisance) and a command of the Observatory of the Aquitaine Coast (2014, at Truc-Vert). It is an airborne Lidar, whose commodities are DEM of metric resolution, to $25 \mathrm{~cm}$ of vertical uncertainty [27]. Resampling on two data has been done from rough point clouds. Final DEM has a spatial resolution of $0.5 \mathrm{~m}$, with $25 \mathrm{~cm}$ of uncertainty.

\subsection{UAV Acquisition and Photogrammetric Protocol}

Since 2016, a $1.7 \mathrm{Kg}$ UAV (DJI Phantom 2) is used to survey Truc-Vert. It is equipped with a black GoPro Hero 4 sensor and a three-axis brushless gimbal. The flight parameters and the success of the missions are provided by a video return of $5.8 \mathrm{GHz}$ system. The drone carried out its missions from a flight plan scheduled at a speed of 5 to $9 \mathrm{~m} / \mathrm{s}$ (depending on the strength of the wind) and a height of $40 \mathrm{~m}$. Several permanent ground control points have been implemented on the dune by using a differential GNSS (PPK method) Trimble R6 [10]. Topographic data are post-processed by using the Trimble software and a nearby permanent GNSS Stationlocated at Royancity.

Since 2016, a drone of $1.4 \mathrm{Kg}$ (DIPhantom 4 pro) is used to survey Plaisance, equipped with a Sony Exmor $120 \mathrm{MP}$ sensor. Flight parameters and the smooth running of the mission are controlled using a connection "Lightbridge" of 2.4 or $5.8 \mathrm{GHz}$. The drone carried out its missions from a flight plan scheduled at a speed of $6 \mathrm{~m} / \mathrm{s}$ and also at the height of $40 \mathrm{~m}$ photographs are taken in port mode, every 2 seconds. Several permanent checkpoints have been established on the dune and other are positioned at each mission on the beach. They are statements (PPK method) to GPS differential TrimbleGEOXH6000. Topographic data are post-processed by using the Trimble software and a nearby permanent GNSS Station located on Aix Island.

All of the acquired photos during field campaigns are then post-processed using the AgisoftPhotoscanPro software. During the photogrammetric treatments, 
shots are aligned. This operation causes some systematic errors (geometric deformations), essentially on the vertical plane (a bit on the longitudinal plan). The bowl effects [28] are more pronounced when lands are very long and little broad. They are corrected by adjusting the precision of cameras alignment, as well as the increase of the density of ground control points (Figure 2).

For each campaign, the drone produces several games of data:

- An ortho-photo with a spatial resolution of 1.5 (Plaisance) and $2.5 \mathrm{~cm}$ (Truc-Vert).

- A Dem with a spatial resolution of $3 \mathrm{~cm}$ (Plaisance) and $2 \mathrm{~cm}$ (Truc-Vert) and whose vertical details are 6 (Plaisance) and $10 \mathrm{~cm}$ (Truc-Vert).

\subsection{Volume Computing with a Vertical Threshold and Topographic Profiles (v1)}

The most used volumes computing method is operated from a vertical threshold. Usually, this vertical delimitation is based on visual estimations of the dune toe or another indicator. This method uses cross-shore profiles from the vertical threshold, and up to a non-mobility point located on the grey dune (Figure 3 ). This setup induces a surface that can be calculated and extrapolated alongshore to obtain a volume, as in the following Equation (1):

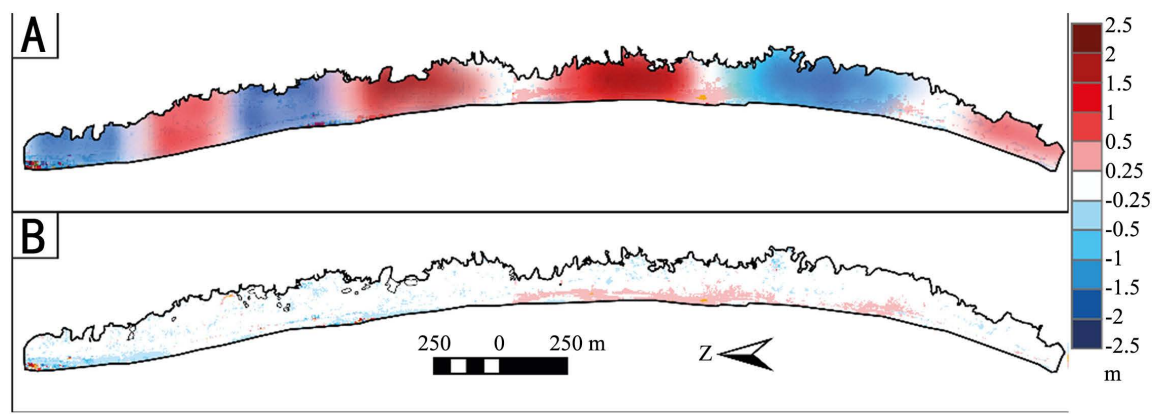

Figure 2. Comparison between UAV data (acquired in 2018/01) and lidar data (acquired in 2016). Faults group with bowl effect (A), topographic differential after correction (B).

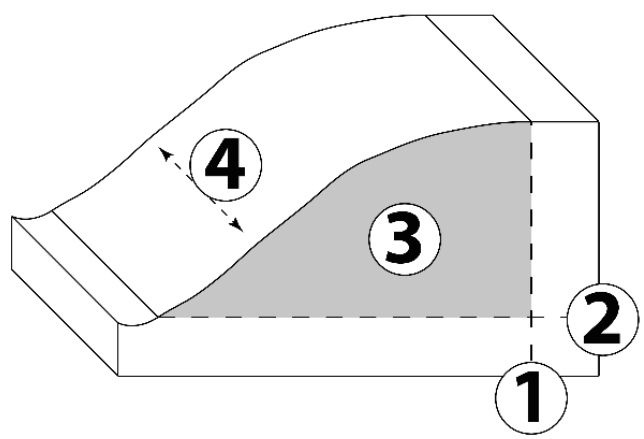

Figure 3. Volume computing using cross-shore profiles: non-mobility point (1), vertical threshold (2), induced surface in profile (3), extrapolated distance between profiles (4). 


$$
v 1=\frac{\sum_{p=1}^{n}(S l)}{L}
$$

where $p$ is a cross-shore profile, Sa surface, $I$ the distance extrapolation between two profiles, $L$ the linear part of the coast concerned by the calculation to get $\mathrm{m}^{3} / \mathrm{m}$ linear alongshore variations.

In this study, dune profiles have been drawn by using the ARCMAP add-on, called DSAS [29]. Transects are drawn every $2 \mathrm{~m}$, with $200 \mathrm{~m}$ of length. Further, each transect is cut into a series of sections of $0.25 \mathrm{~m}$, by averaging the topography. The surface of all the profiles is therefore calculated as follows (Equation (2)):

$$
v 1=\frac{\sum_{p=1}^{n}\left(\sum_{t=1}^{n}\left(d\left(\bar{x}^{\mathrm{T}}-v t\right)\right) l\right)}{L}
$$

where $p$ is a profile topographic cross shore, $t$ a stretch of $0.25 \mathrm{~m}, d$ the distance of $t, \bar{x}^{\mathrm{T}}$ the average of the topographical values on the distance $d, v t$ is the vertical threshold, $L$ the linear part of the coast concerned by the calculation to get $\mathrm{m}^{3} / \mathrm{m}$ alongshore variations.

\subsection{Volume Computing Using a Vertical Threshold and a Polygon Surface ( $v 1)$}

This variant method does not use cross-shore profiles, but a surface (Figure 4). Volumes are then computed according to the following Equation (3):

$$
v 2=\frac{\sum_{P=1}^{n}((P-v t) S p)}{L}
$$

where $P$ a pixel of the digital terrain model, $v t$ the vertical limit, $S P$ the pixel surface of the DEM, $L$ the linear part of the coast concerned by the calculation to get $\mathrm{m}^{3} / \mathrm{m}$ alongshore variations.

In this study, the vertical limit is subtracted to the terrain through the use of a raster calculator. The terrain so calculated is then converted in Digital Volumes Model (DVM), using the surface of each pixel. Beachside, the limit is extracted by making an isocontour at a given altitude. On land, the no mobility limit can be traced "by hand" or making a topographic differential with the extraction of an isocontour to 0 . All of the two boundaries (sea and land) can then be assembled to obtain a polygon. The volume is then calculated by summing all of the pixels of the DVM in the surface of the polygon.

If several polygons are used to illustrate alongshore variability, all polygons must be summed to provide the total balance of the evolutions of the site under study ( $v 2 e$ ), according to the following Equation (4):

$$
v 2 e=\frac{\sum_{E=1}^{n}\left(\sum_{P=1}^{n}((P-v t) S p)\right)}{L}
$$

where $E$ is a topographic influence (polygon), $P$ a pixel of the digital terrain model, $v t$ the vertical limit, $S P$ the pixel surface of the DEM, $L$ the linear part of the coast concerned by the calculation to get $\mathrm{m}^{3} / \mathrm{m}$ alongshore variations. 


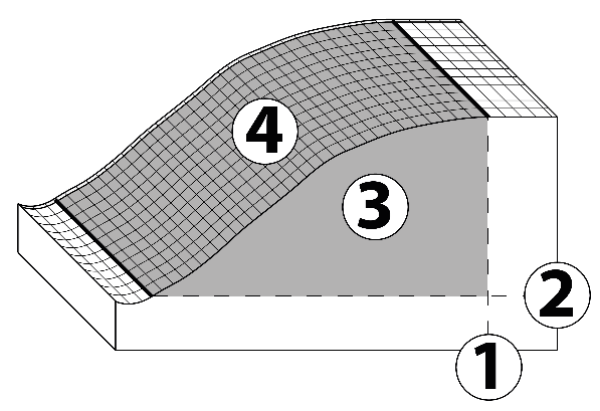

Figure 4. Volume computing using a surface: non-mobility point (1), vertical threshold (2), induced surface in profile (3), field surface (polygon) (4).

\subsection{Vertical Threshold Delimitation}

The vertical limit used for the site of Truc-Vert was determined at $7 \mathrm{~m}$ above mean sea level, by visual observations [15]. We kept this delimitation to determine applicability. The vertical limit used for the site of Plaisance was determined at $6.2 \mathrm{~m}$ above mean sea level. This value has been obtained after having photo-interpreted the dune toe position and calculated its topographic average in 2010 and 2017.

\subsection{Photo-Interpretation of the Dune Toe}

In checking the dune toe position compared to the vertical threshold, the dune toe is photo-interpreted for each field date. Parameters are a slope break: by using the dip and shadingrasters, computed from the DEM. This slope break is complemented by the interpretation of the vegetation limit, visible on every high-resolution aerial photography. This dune toe indicator is commonly used in coastal studies [5] [12]. Spatial resolutions associated with the images are detailed in Table 1.

\subsection{Error Computing of $v 1$ and $v 2$}

Regarding dune toe mobility, the associated error with the use of a fixed vertical limit may be calculated by comparing the photo-interpreted dune toe and the one obtained by using an isocontour of the vertical limit. The merger of these two limits draws a polygon from which calculations can be achieved. Beforehand, given that all of the volumes are calculated from a vertical limit, values must be converted to absolute values.

Table 1. Cell size overview of the orthophotographydataset.

\begin{tabular}{cccc}
\hline & Date & Cell size $(\mathrm{m})$ & Vector \\
\hline \multirow{3}{*}{ Truc-Vert } & November 2014 & 0.1 & Plane \\
& $25 / 01 / 2016$ & 0.03 & UAV \\
& $23 / 01 / 2018$ & 0.3 & UAV \\
Plaisance & Summer 2010 & 0.25 & Plane \\
& November 2017 & 0.015 & UAV
\end{tabular}


The Equation (5) used for computing the error of v1 is:

$$
\varepsilon v 1=\frac{\sum_{p=1}^{n}\left(\sum_{t=1}^{n}(d l(|Z-v t|))\right)+\varepsilon I}{L}
$$

where $p$ is a cross-shore profile, $t$ a stretch of $0.25 \mathrm{~m}, d$ the distance of $t, \bar{x}^{\mathrm{T}}$ the average of the topographical values on the distance $d, L$ the linear part of the coast concerned by the calculation to get $\mathrm{m}^{3} / \mathrm{m}$ alongshore variations, $\varepsilon I$ the instrumental error (RMSE) associated with acquisitions as well as photogrammetric protocol.

The Equation (6) used to calculate the $v 2$ error is:

$$
\varepsilon v 2=\frac{\sum_{P=1}^{n}((|Z-v t|) S p)+\varepsilon I}{L}
$$

where $P$ is a pixel of the DEM, $Z$ the topographic value $P, v t$ the vertical limit, $S P$ the pixel surface of the DEM, $L$ the linear part of the coast concerned by the calculation to get $\mathrm{m}^{3} / \mathrm{m}$ alongshore variations, $\varepsilon I$ the instrumental error (RMSE) associated with acquisitions as well as photogrammetric protocol.

\subsection{Volume Computing with a Dune Field Adapted to Cut and Fill Method (v3)}

To better integrate the intrinsic mobility to the dune system, we developed another approach for volume calculations. This alternative is an adaptation of the principle of the cut/fill to the dune and coastal environment (Figure 5). The use of this method implies to define the dune toe position and main reliefs of the dune (scarped foredune but also the summit and the other side of the dune). The identification of these morphological elements is based on a photo-interpretation and an automatic extraction of slope-outs. To take into account the dune toe position variability, during the phases of erosion (steps back and lowers) or accretion (progress seaward and raises), we operate a differential between two DEM's (so at least two measures are required to start). From polylines thus extracted, result polygons of erosion or accretion. These polygons are then merged to other polygons. Therefore, it is first necessary to calculate a differential of DEM and convert it into DVM (on each pixel), according to the following Equation (7):

$$
D V M=(D E M 2-D E M 1) S p
$$

where $D E M 1$ is the oldest measurement, $D E M 2$ is the most recent, $S p$ the pixel surface of the resulting differential.

The Equation (8) used to calculate volume from a DVM is:

$$
v 3=\frac{\sum_{c=1}^{n}(A)+\sum_{c=1}^{n}(E)+\sum_{c=1}^{n}(C)}{L}
$$

where $c$ is a unit of $D V M, A$ the spatial influence of sectors in accretion, $E$ the spatial influence of erosion areas, $C$ the rest space rights-of-way, $L$ the linear part of the coast concerned by the calculation to get $\mathrm{m}^{3} / \mathrm{m}$ alongshore variations. 




Figure 5. Presentation scheme of the cut/fill method adapted for coastal sand dunes: cross-shore view in the case of an accretion (A), cross-shore view in the case of an erosion (B), nadir view form the two integrated situations (C); new dune toe position (1), old dune toe position (1'), non-mobility point (2), rest of the dune (3).

If several polygons are used to illustrate a longshore variability, all polygons must be ordered for the total balance of the evolutions of the site under study volumes ( $13 e$ ), according to the following Equation (9):

$$
v 3 e=\frac{\sum_{P=1}^{n}\left(\sum_{c=1}^{n}(A)+\sum_{c=1}^{n}(E)+\sum_{c=1}^{n}(C)\right)}{L}
$$

where $P$ is a surface (polygon).

The associated error with this method (Equation (10)) boils down to the error related to the instruments deployed in the various protocols and that related to the photogrammetric protocol. By combining them, we get a total error not exceeding $10 \mathrm{~cm}$ at Truc-Vert and $5.6 \mathrm{~cm}$ at Plaisance.

$$
\varepsilon \vee 3=\frac{n \varepsilon I}{L}
$$

where $n$ is the number of cells used to calculate $v 3$ and $\varepsilon I$ the error (RMSE) related to acquisitions as well as photogrammetric protocol.

\subsection{Synthesis Flow Chart}

A synthesis flow chart is presented to illustrate all of the previous computing (Figure 6).

\section{Results}

\subsection{Shoreline Delimitation Variability}

For the site of the Truc-Vert, deviations in position of the dune toe between the isocontour and the photo-interpretation vary according to the dates (Figure 7). The Lidar is the date whose positions are the closest (2014). The distances between the two tracks range from 1.2 to $4.9 \mathrm{~m}$, with an average of $2.2 \mathrm{~m}$. To this 




Figure 6. Synthesis flow chart.

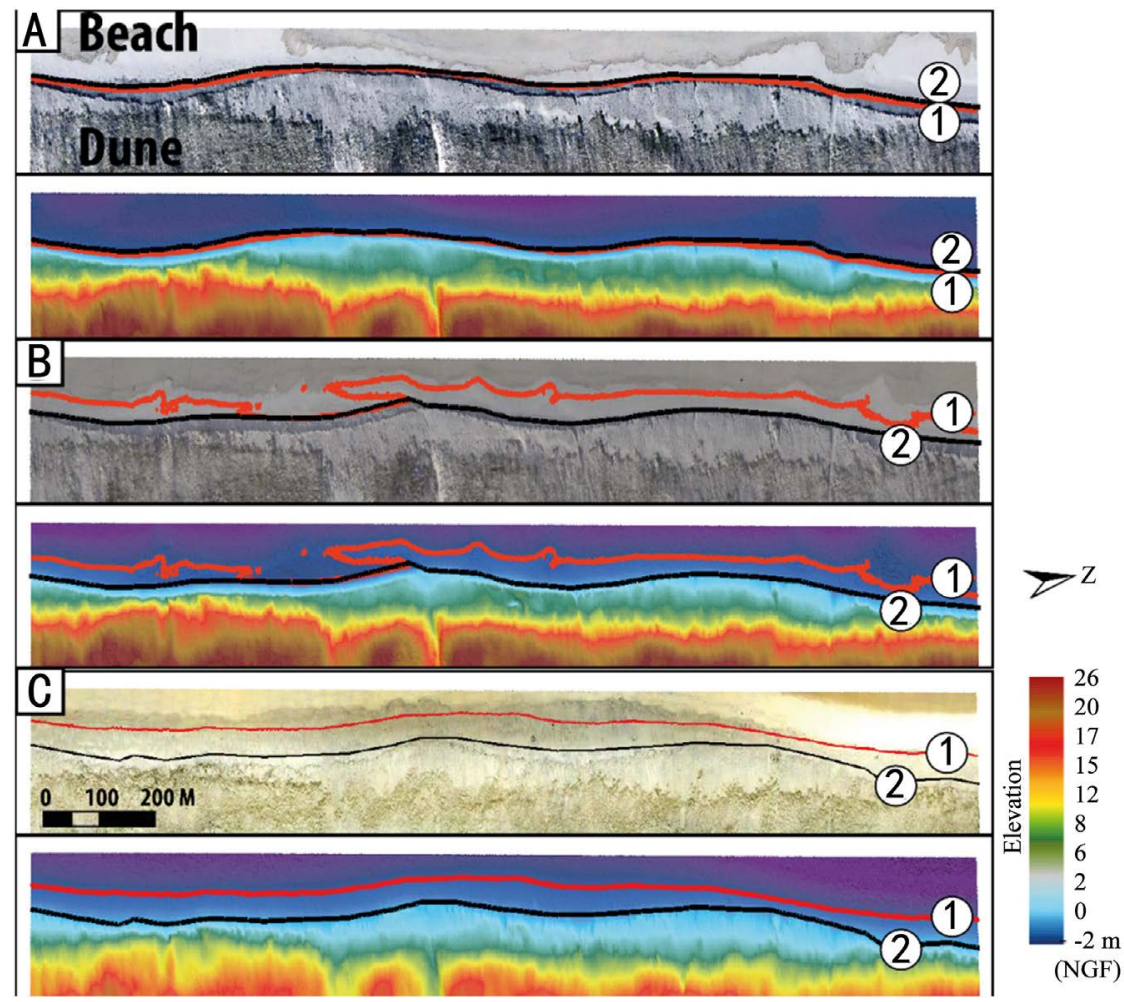

Figure 7. Dune toe delimitation at Truc-Vert. for 2014 lidar (A), 2016/01 data (B), 2018/01 data (C); isocontour (1), photo-interpreted (2). For each date: orthophotography (on the top) and DEM (bottom).

date, two polylines that define the dune toe follow perfectly the morphology of the dune. At the time of the acquisition, the dune is very scarped, due to the impact of winter 2013-2014 [16]. In this case, the vertical delineation of the dune toe is easier. For the other two dates (2016 and 2018), the differences between the two-dune toe delimitation vary strongly. In 2016, the isocontour seems to 
follow topographical reconstruction of the upper beach. The route differs entirely from dune toe drawn by photo-interpretation. The distance between the two tracks varies from 0 to $18.6 \mathrm{~m}$, with an average of $10 \mathrm{~m}$. The situation is similar in 2018, except that the isocontour is more linear than in 2016. There remains a significant gap between the isocontour and the photo-interpreted dune toe. The distance between the two tracks varies from 7.2 to $20.4 \mathrm{~m}$, with an average of $15.8 \mathrm{~m}$.

At Plaisance, control of boating sector also presents significant differences between values bounded by photo-interpreted and by isocontour (Figure 8). This gap is especially important towards the center of the area, due to the emergence of an embryonic dune. In 2010, the gaps between the dune toe boundaries were of average $3 \mathrm{~m}$ (envelope from 0 to $24 \mathrm{~m}$ ). However, in 2017, the isocontour is closer to the photo-interpreted limit, with a medium gap between the two-dune toes of $0.5 \mathrm{~m}$ (envelope from 0 to $14 \mathrm{~m}$ ).

\subsection{Longshore Altimetric variability of the Dune Toe}

The gap between the isocontour and photo-interpreted delineations is shaped by elevation changes in the dune toe along the coastline (Figure 9). At Plaisance, in 2010 the altitude of the dune toe is changing between 1 and $7 \mathrm{~m}$ (average of 4.7 $\mathrm{m})$. In 2017, the average has changed little $(5.1 \mathrm{~m})$, with the intervals tending to decrease. This reduction in spreads is likely related to the reconstruction of an embryonic dune. At Truc-Vert, changes in are constantly positive. In 2014, the interval was going from 4.3 to $5.8 \mathrm{~m}$ (average of $5 \mathrm{~m}$ ). These small differences are explained by the fact that the dune was heavily cut to cliff during the winter before the lidar survey, so that topography was quite uniform on this sector. In 2016, the interval increases significantly, with values ranging from 5.2 to $8.6 \mathrm{~m}$ (average of $7 \mathrm{~m}$ ). In 2018, the altitude of the dune toe varies between 7.4 and 10 $\mathrm{m}$ (average of $8.5 \mathrm{~m}$ ).

\subsection{Estimated Volumes Differences and Methodological Bias}

The common point between $\mathrm{v} 1$ and $\mathrm{v} 2$ methods is the use of an arbitrary delineation of the dune toe. As already observed, this one is often not consistent with the field reality. As it comes to calculate volumes from this setting, more or less significant errors will result. Our observations show that this is particularly the case when the position of the dune toe is changing rapidly (during erosion or reconstruction phases). These errors appear minimal as reported to the volumes of the dunes, since they are consistently lower than $1 \%$. If we look at variations of volume, by differentials between each statement, at this scale errors become significant. Differential after differential, they will sometimes be cumulated (Figure 10(a)). If a phase of erosion and reconstruction are linked (or vice versa) between surveys, incidentally the error may cancel (Figure 10(b)). If the dynamic continues, cumulative errors exceed the calculated volumes differential which is not without consequence in the interpretation that we can give. 
The method of calculation by embankments, cuttings, which does not suffer from this way, allows checking the differentials of volumes calculated using v1 (Table 2) and v2 (Table 3).

For the site of Truc-Vert, the error associated with the 2014-2016 differential exceeds $100 \%$ of the calculated variation of volumes. The differential 2016-2018 gives a significant degree of error but any remaining (nearly 90\%).

For the site of Plaisance, the approximation is less critical, with a degree of error varying from $30 \%$ to $35 \%$. In 2017 , the dune toe bounded by isocontour was very close to the dune toe photo-interpreted (gap less than $1.0 \mathrm{~m}$ ). Mobilized volumes are also smaller, making it easier to estimate and limit the margin of error.

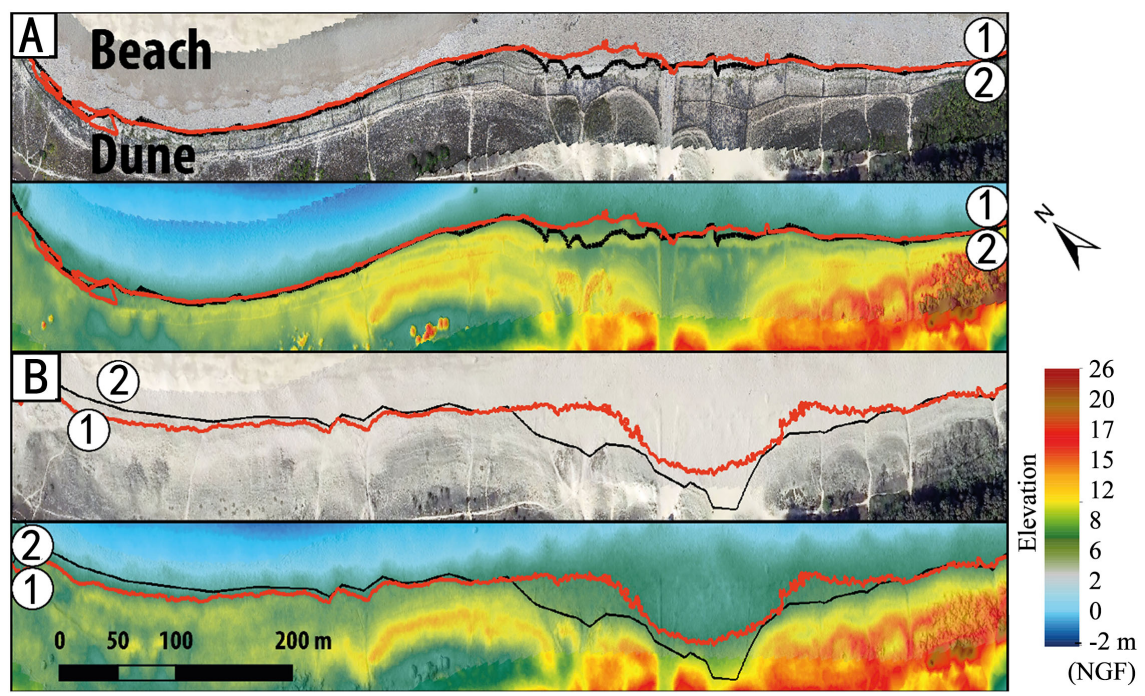

Figure 8. Dune toe delimitation for Plaisance: for 2014 lidar (A), 2016/01 data (B), 2018/01/23 data (C); isocontour (1), photo-interpreted (2). For each date: orthophotography (on the top) and DEM (bottom).

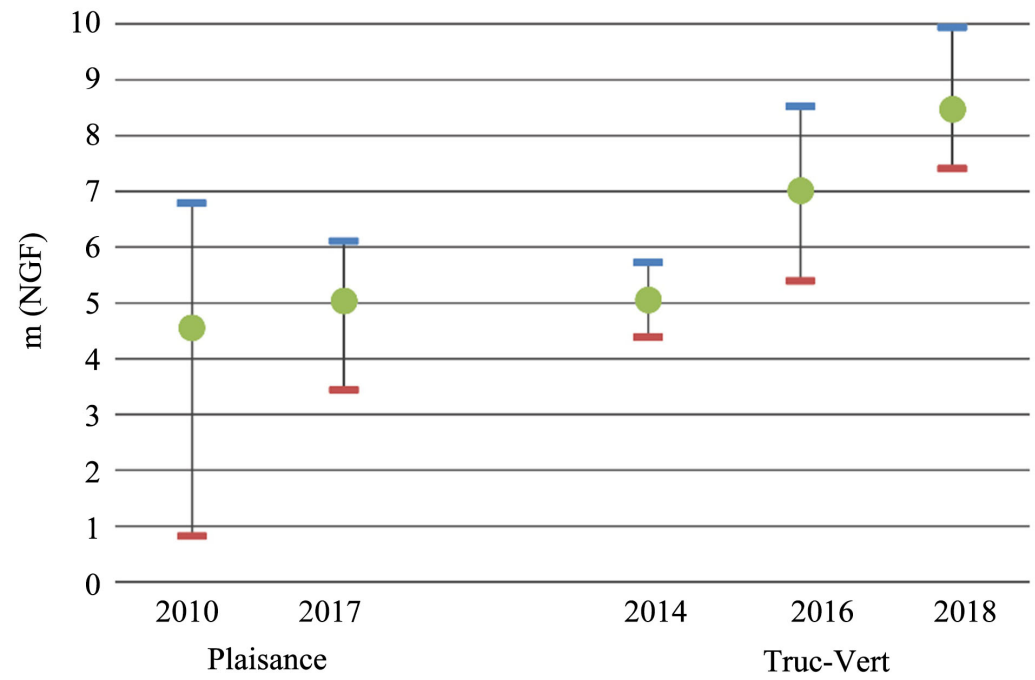

Figure 9. Altimetric variation of the dune to eat each studied site. 


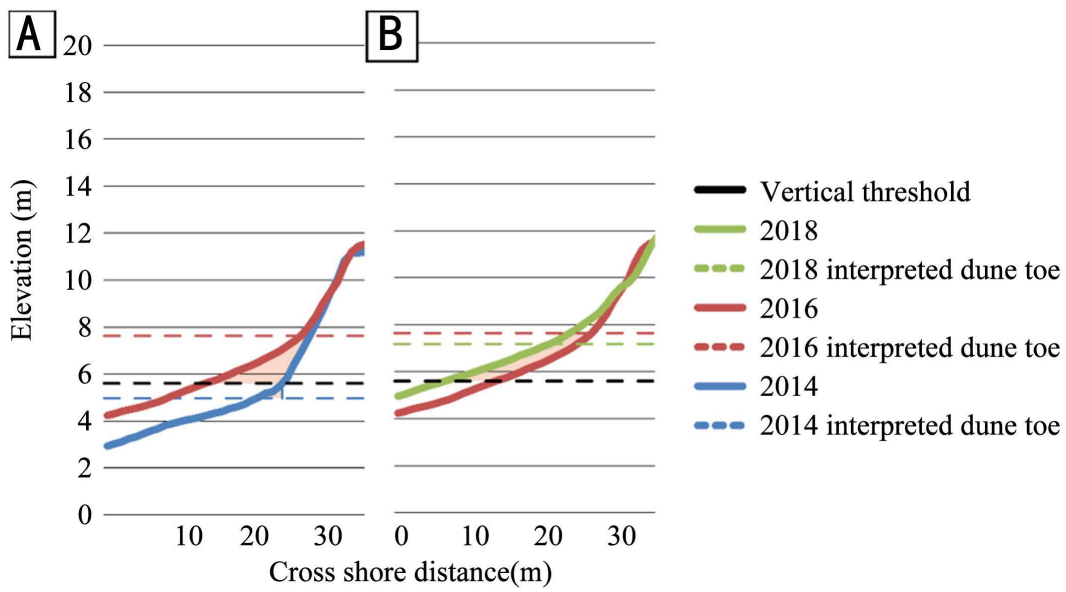

Figure 10. Error visualization: cumulated (A), cancelled (B).

Table 2. Computed volumes (en $\mathrm{m}^{3} / \mathrm{m}$ ) and total associated errorsat Truc-Vert.

\begin{tabular}{ccccccc}
\hline & $2014-2016$ & $\varepsilon 2014-2016$ & $\% \varepsilon$ & $2016-2018$ & $\varepsilon 2016-2018$ & $\% \varepsilon$ \\
\hline$v 1$ & 10 & 12 & $120 \%$ & 33 & 29 & $88 \%$ \\
$v 2$ & 11 & 12 & $109 \%$ & 34 & 29 & $87 \%$ \\
$v 3$ & 14 & 1 & $9 \%$ & 21 & 2 & $8 \%$ \\
\hline
\end{tabular}

Table 3. Computed volumes (en $\mathrm{m}^{3} / \mathrm{m}$ ) and total associated errors at Plaisance.

\begin{tabular}{cccc}
\hline $\boldsymbol{2} 1$ & $\mathbf{2 0 1 0 - 2 0 1 7}$ & $\boldsymbol{\varepsilon} \mathbf{2 0 1 0 - 2 0 1 7}$ & $\% \varepsilon$ \\
$\boldsymbol{v} 2$ & 6 & 2 & $31 \%$ \\
$v 3$ & 5 & 2 & $35 \%$ \\
\hline
\end{tabular}

\section{Discussion}

The use of vertical limits, to calculate sand volume variations, seems to be sometimes unadapted for coastal dune environments. Especially those where morphodynamics are very variable in time and offer a large range of variation in extends. Cumulated errors ensued from this method are quite difficult to quantify. We developed a protocol to take up the issue, based on other physical indicators performed by computer-assisted photo-interpretation. Results and comparison of the available approaches incite us to work on the assumption that, in some cases, errors in the calculation of volumes can exceed the measured field variation itself. The verification process is illustrated in this paper through two distinct study sites. Besides, this work was performed on several other configurations along the French coast.

A vertical limit is relevant in the case of coastal features which are not influenced by the variation of the dune toe position. As in the example of a parabolic dune located at the top of the foredune and evolving toward the grey dune we survey from years [30]. Easy to determinate (visual estimation) and perform (a 
unique value all along the shore), the method can be preferred to other approaches because of these advantages. On the contrary, when morphodynamics observed rely on the dune toe position and where this one is very variable, another method needs to be performed. Thus, our alternative based on the topometric cut and fill concept is much more adapted in such configurations.

As the main advantage, this method allows us to better integrate landform variability. In the case of coastal dunes, we can accurately identify the dune toe but also any physical indicator involving slope disruptions (top of the dune, bulges and cavities). A beforehand cross-shore and long-shore compartment of the dune is then sufficient, as shown in (Figure 11). Errors generated by this approach do exist. The first one is directly due to the physical indicator technics of delineation. Verification of the process of data production is thus essential. For example, every automatic extraction of slope breaks needs to be compared with photo-interpretation, and if necessary corrected a posteriori. The second one is due to the geomatic process itself, when polygons obtained intersect raster cells from the input DEM's. Cumulated errors were estimated for Plaisance and Truc-Vert and give values varying from $0.3 \%$ to $3 \%$, which is quite acceptable.

This protocol was applied at Truc-Vert form a high resolutions UAV survey performed between October 2016 and January 2018 (Figure 12). Selected physical indicators allowed us to calculate sand volume variation at each part composing the beach and dune system, from whom a global volume can be summed. As a result, sand erosion and deposition are spatially identified with a high rate of accuracy. Such a decomposition of coastal features, at high resolution, both cross-shore and long-shore, is useful for refining morphological analysis.

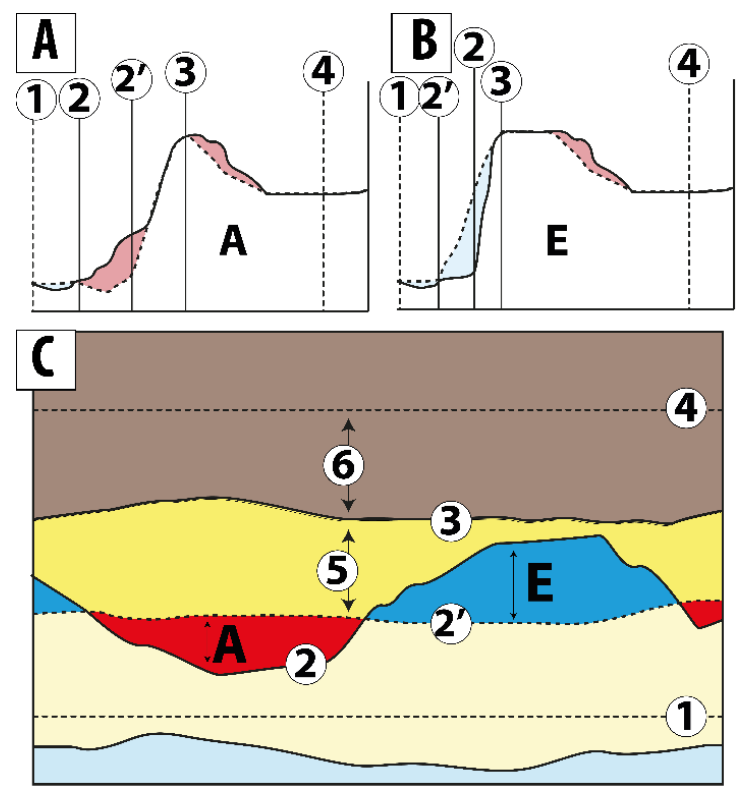

Figure 11. Example of cut and fill method improvements, with: seaward limit of measurements (1), variable position of the dune toe in a context of accretion (2), variable position of the dune toe in a context of erosion (2'), medium limit on the foredune (3), non-mobility limit (4), white dune (5), grey dune (6). 


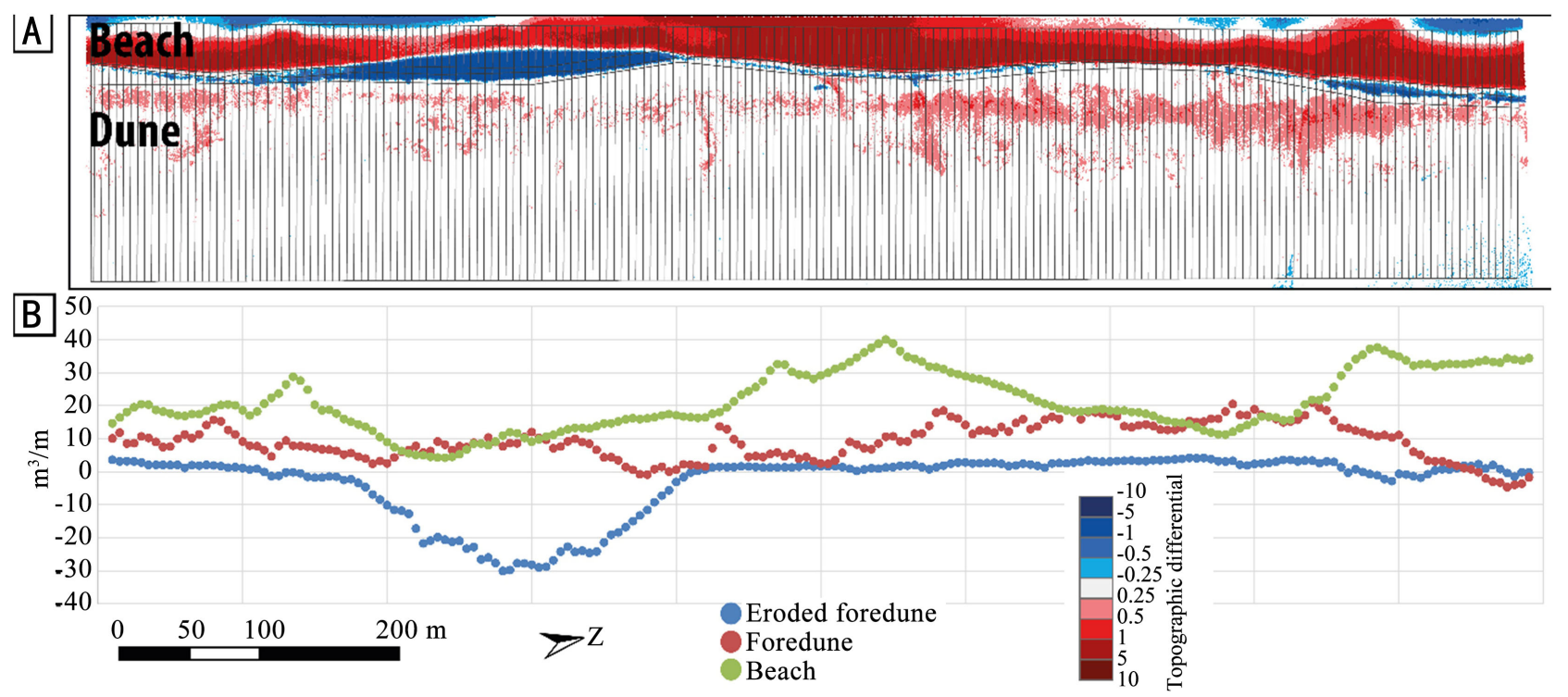

Figure 12. Example of the application at Truc-Vert, with the topographic differential between 2016 and 2018 (A), a variety of volume variation $\left(\mathrm{m}^{3} / \mathrm{m}\right)$ for each compartment of the dune $(B)$.

\section{Conclusions}

This study indicates that using arbitrary defined vertical limits is not the only way to calculate beach and dune volume variations. As shown through the examples of Plaisance and Truc-Vert, the method suffers from imprecision that conduces to underestimate the potential variability of the dune toe position. In some cases, beach and dune morphological mobility are too wide and call the method relevancy in question. In this paper, we wanted to focus on this problem, developed a geomatic protocol to quantify associated errors and then tried to develop an alternative method of sand volume calculation.

The main reason why the vertical limit is sometimes unadapted is that beach and dune do not have the same rates of recovery [21]. The dune toe is materialized by an embryonic dune partially covered by pioneer vegetation. This implies topographic heterogeneity, both cross-shore and long-shore. Ignoring these essential elements, mobility and heterogeneity, lead to wrong results and false analysis. The combination of a high-resolution photogrammetric data survey and the use of a derived cut and fill topographic method allowed us to significantly reduce errors associated with sand volume calculation and to better estimate the beach and dune morphodynamics.

This work offers several leads of development and numerous perspectives. Furthermore, an improving of our adaptive cut and fill method could be applied with the use of multispectral images of coastal sand dunescollected via UAV. These additional measurements could enable us to increase the number and quality of parameters from whom we delineate the dune reliefs. Otherwise, itwould allow us to better integrate the role of vegetation cover and its interactions with the dune morphodynamics, by using remote sensing technics and various imagery processings. 


\section{Conflicts of Interest}

The authors declare no conflicts of interest regarding the publication of this paper.

\section{References}

[1] Pilkey, O.H., Éd. (2011) The World's Beaches: A Global Guide to the Science of the Shoreline. University of California Press, Berkeley.

[2] Cohen, J.E. (1997) Estimates of Coastal Populations. Science, 278, 1209-1213. https://doi.org/10.1126/science.278.5341.1209c

[3] Ghermandi, A. and et Nunes, P.A.L.D. (2013) A Global Map of Coastal Recreation Values: Results from a Spatially Explicit Meta-Analysis. Ecological Economics, 86, 1-15. https://doi.org/10.1016/j.ecolecon.2012.11.006

[4] Cazenave, A., Dieng, H.-B., Meyssignac, B., von Schuckmann, K., Decharme, B. and et Berthier, E. (2014) The Rate of Sea-Level Rise. Nature Climate Change, 4, 358-361. https://doi.org/10.1038/nclimate2159

[5] Fletcher, C., Rooney, J., Barbee, M., Lim, S.-C. and et Richmond, B. (2004) Mapping Shoreline Change Using Digital Orthophotogrammetry on Maui, Hawaii. Journal of Coastal Research, SI 38, 106-124.

[6] Benoît, G., Bruno, C. and et Vincent, M. (2016) An Update on Shoreline Evolution in SW France Using Diachronic Analysis of Ortho-Rectified Photos Since 1950. (Unpublished)

[7] Lee, I.-C.J., Wu, B. and et Li, R. (2009) Shoreline Extraction from the Integration of Lidar Point Cloud Data and Aerial Orthophotos Using Mean Shift Segmentation.

[8] Gonçalves, J.A. and et Henriques, R. (2015) UAV Photogrammetry for Topographic Monitoring of Coastal Areas. ISPRS Journal of Photogrammetry and Remote Sensing, 104, 101-111. https://doi.org/10.1016/j.isprsjprs.2015.02.009

[9] Guillot, B. and et Pouget, F. (2015) UAV Application in Coastal Environment, Example of the Oleron Island for Dunes and Dikes Survey. ISPRS-International Archives of the Photogrammetry, Remote Sensing and Spatial Information Sciences, XL-3/W3, 321-326. https://doi.org/10.5194/isprsarchives-XL-3-W3-321-2015

[10] Guillot, B., Castelle, B., Marieu, V., Bujan, S. and et Rosebery, D. (2018) UAV Monitoring of 3-Year Foredune Partial Recovery from a Severe Winter: Truc Vert Beach, SW France. Proceedings from the International Coastal Symposium (ICS) 2018, Busan, Republic of Korea, May 2018, 276-280.

http://www.bioone.org/doi/10.2112/SI85-056.1

[11] Almonacid-Caballer, J., Sánchez-García, E., Pardo-Pascual, J.E., Balaguer-Beser, A.A. and et Palomar-Vázquez, J. (2016) Evaluation of Annual Mean Shoreline Position Deduced from Landsat Imagery as a Mid-Term Coastal Evolution Indicator. Marine Geology, 372, 79-88. https://doi.org/10.1016/j.margeo.2015.12.015

[12] Castelle, B., et al. (2018) Spatial and Temporal Patterns of Shoreline Change of a 280-km High-Energy Disrupted Sandy Coast from 1950 to 2014: SW France. Estuarine, Coastal and Shelf Science.

[13] Pouget, F. (1988) Télédétection et végétation du milieu dunaire aquitain: Identification des facies de la dune littorale à partir de données du satellite Spot. PhD Thesis.

[14] Ash, J.E. and et Wasson, R.J. (1983) Vegetation and Sand Mobility in the Australian Desert Dunefield. Zeitschrift fur Geomorphologie, 45, 7-25. 
[15] Castelle, B., Bujan, S., Ferreira, S. and et Dodet, G. (2017) Foredune Morphological Changes and Beach Recovery from the Extreme 2013/2014 Winter at a High-Energy Sandy Coast. Marine Geology, 385, 41-55. https://doi.org/10.1016/j.margeo.2016.12.006

[16] Castelle, B., et al. (2015) Impact of the Winter 2013-2014 Series of Severe Western Europe Storms on a Double-Barred Sandy Coast: Beach and Dune Erosion and Megacusp Embayments. Geomorphology, 238, 135-148. https://doi.org/10.1016/j.geomorph.2015.03.006

[17] Anthonsen, K.L., Clemmensen, L.B. and Jensen, J.H. (1996) Evolution of a Dune from Crescentic to Parabolic Form in Response to Short-Term Climatic Changes: Råbjerg Mile, Skagen Odde, Denmark. Geomorphology, 17, 63-77. https://doi.org/10.1016/0169-555X(95)00091-I

[18] Masselink, G., et al. (2016) Extreme Wave Activity during 2013/2014 Winter and Morphological Impacts along the Atlantic Coast of Europe: Extreme Atlantic Waves during 2013/2014. Geophysical Research Letters, 43, 2135-2143. https://doi.org/10.1002/2015GL067492

[19] Suanez, S., Cariolet, J.-M., Cancouët, R., Ardhuin, F. and Delacourt, C. (2012) Dune Recovery after Storm Erosion on a High-Energy Beach: Vougot Beach, Brittany (France). Geomorphology, 139-140, 16-33. https://doi.org/10.1016/j.geomorph.2011.10.014

[20] Morton, R.A., Paine, J.G. and Gibeaut, J.C. (1994) Stages and Durations of Post-Storm Beach Recovery, Southeastern Texas Coast, USA. Journal of Coastal Research, 10, 884-908.

[21] Houser, C., Wernette, P., Rentschlar, E., Jones, H., Hammond, B. and Trimble, S. (2015) Post-Storm Beach and Dune Recovery: Implications for Barrier Island Resilience. Geomorphology, 234, 54-63. https://doi.org/10.1016/j.geomorph.2014.12.044

[22] Hesp, P. (2011) Dune Coasts. In: Treatise on Estuarine and Coastal Science, Elsevier, New York, 193-221. https://doi.org/10.1016/B978-0-12-374711-2.00310-7

[23] Bramato, S., Ortega-Sánchez, M., Mans, C. and Losada, M.A. (2012) Natural Recovery of a Mixed Sand and Gravel Beach after a Sequence of a Short Duration Storm and Moderate Sea States. Journal of Coastal Research, 279, 89-101. https://doi.org/10.2112/JCOASTRES-D-10-00019.1

[24] Anthony Stallins, J. and Corenblit, D. (2018) Interdependence of Geomorphic and Ecologic Resilience Properties in a Geographic Context. Geomorphology, 305, 76-93. https://doi.org/10.1016/j.geomorph.2017.09.012

[25] Chaffin, B.C. and Scown, M. (2018) Social-Ecological Resilience and Geomorphic Systems. Geomorphology, 305, 221-230. https://doi.org/10.1016/j.geomorph.2017.09.038

[26] Holling, C.S. (1973) Resilience and Stability of Ecological Systems. Annual Review of Ecology and Systematics, 4, 1-23. https://doi.org/10.1146/annurev.es.04.110173.000245

[27] Jolivet, P. and Lamarre, V. (2008) Litto3D V 1.0 Spécifications Techniques V 1.4. IGN, SHOM.

[28] Tournadre, V., Pierrot-Deseilligny, M. and Faure, P.H. (2015) UAV Linear Photogrammetry. International Archives of the Photogrammetry, Remote Sensing 
and Spatial Information Sciences, 40, 327-333.

https://doi.org/10.5194/isprsarchives-XL-3-W3-327-2015

[29] USGS (2016) Department of the Interior, DSAS 4.0, Installation, Instructions and User Guide, Updated for Version 4.3.

[30] Guillot, B., Regnauld, H., Musereau, J. and Pouget, F. (2018) High Frequency UAV Survey of a Parabolic Sand dune Evolution in Gurp Bay (France) from 2011 to 2018. 